\title{
The role of the training programme director
}

\author{
Asif Ali
}

One blustery autumn afternoon sometime in the past decade, I made my way to Milton Keynes Hospital to see someone who was on a 'mandatory' list of people to meet. I had been shortlisted for the training rotation in diabetes and endocrinology in the Oxford deanery. I was not particularly optimistic about my chances of being appointed, but I had received good advice from my then consultants that I should meet the training program director (TPD) to discuss the rotation, show keenness and have a 'chat'. It being my first time in Milton Keynes, I could not help but be impressed with the tree-lined boulevards and the relative paucity of vehicular traffic. I was later informed by people in the know (in that pre-Wikipedia era) that this was thanks to the grid system and clever design of the roads. Well, first mystery solved. But what was the role of the 'training programme director' (TPD) whom I was about to meet? Perhaps another quasi-educationalist who worked from a smart office in the deanery?

My preconceptions could not have been further from the truth. Throughout my training, my TPD provided a muchneeded sense of continuity amidst frequent changes of hospitals, new trainers and so on. He was my mentor, guide and, at the end of my training, the person who found me a job (well, he retired and I became him!).

The TPD does not really have a clearly defined job description. $\mathrm{He} / \mathrm{she}$ (henceforth referred to as I or me) is answerable to the head of the medical school and the postgraduate dean. At the very least, the TPD is required to deliver an annual report to the deanery, which then collates such information from all of its TPDs and submits it to the GMC. That is the pen-pushing side of the job and hardly worth discussing further.

ST3 interviews are a truly exciting time for me. I get to meet, for the first time, all of the trainees who will go further than many of their peers over the next five or so years, discovering new things and pushing the frontiers of our understanding of diabetes and endocrinology along the way. They will pay their dues to society by providing a vast amount of service as they undergo their training and emerge at the other end as competent, polished consultants who are able to hit the ground running. Your TPD is likely to start to get to know you from the minute you walk into that interview room.

Every December, it is time for me to stare at the dreaded spreadsheet as I organise the rotation for August the following year. How difficult can it be? If there are 15 trainees in the clinical rotation, six might be doing research and a further three academic clinical fellowships. Now, throw into the mix two more who have been successful in obtaining prestigious research fellowships and beautiful babies born to three of the trainees, two

Asif Ali, consultant physician and training program director in diabetes and endocrinology, South Central (Oxford Rotation) of whom want to go $60 \%$ part time. Add to that requests for more tertiary training to meet requirements such as training in thyroid cancer clinics and paediatric endocrinology. One interdeanery transfer has been approved and, to top it all, one of the training posts has been closed due to the current financial situation. A very interesting mix indeed and a scenario that is not atypical of those which TPDs juggle constantly. Trainees, speak to your TPD early if you anticipate any such complications and life will become that little bit easier.

My job is not to micromanage training but predominantly one of overview. I do take an interest in the way the curriculum is delivered, but one or more of the trainees take charge of designing the teaching program, requesting speakers, collecting feedback and making improvements to this process.

As far as designing the curriculum itself is concerned, as a member of the Specialist Advisory Committee (SAC) of the RCP, the TPD has some input. It is essential, therefore, that issues regarding the curriculum are brought to the attention of the TPD so that they can be addressed.

It is difficult to go through five years or more of training and not have any glitches along the way. Many such problems are just minor niggles and are self-limiting. Occasionally, further help and intervention are required. As a TPD, I always have the interests (long-term, I hasten to add) of the trainees at heart. I will provide as much help and support as is possible to see trainees through challenging times. Thankfully, the vast majority of trainees want to do well and perform to an outstanding standard. Despite maximal remedial support, however, there are rare instances when collision with the iceberg seems inevitable. In these circumstances, the TPD has to exercise his duty to safeguard patients and, in exceptional situations, suggest alternative career options. Thankfully, such action is rarely required but it remains an important part of my job. Trainees within a rotation are answerable to the TPD and are bound by an educational contract (many do not realise this).

Emerging from the other end of the training, after five or more years, most trainees know what sort of job they would like to do, and again the TPD can help. Through their SAC network they usually know of jobs coming up around the country and might well have a channel of communication with the right people. Many TPDs also have the honour of providing 'aftercare' to trainees who are now colleagues, some in this country and others around the world. I love to catch up with my trainees who are now consultants, sometimes providing an opinion on some matter or, more importantly, sometimes just for a chat.

As with any other relationship, you are likely to get back what you invest. It's important that trainees use their TPD to guide them along the way and let them know what's going on. If you have a trainee in difficulty or are struggling yourself and need 
assistance, ask your TPD. You might find that they are not another pen-pushing deanery official. They might not even have an office! Theirs might be one of those email addresses you want to have handy.

If you are a core trainee interested in a career in diabetes and endocrinology, or if you are already an $S p R / S t R$ and would like to have a chat about applying for an ST3 post in D\&E, do write to me.

Address for correspondence: Dr A Ali, Department of Medicine, Milton Keynes Hospital NHS Foundation Trust, Standing Way, Eaglestone, Milton Keynes,

Buckinghamshire, MK6 5LD.

Email: endocrinologypd@gmail.com

\section{A year in the Medicinal Garden of the Royal College of Physicians}

\section{Dr Henry Oakeley revised edition}

The RCP medicinal garden contains over 1,000 different plants that are used, or have been used, in medicine during the past two millennia, and ones that commemorate physicians. This illustrated garden journal describes some of the plants as they flower, week by week, through the seasons. There is also a commentary on their uses, past and present, and space for your notes throughout the year.

Published: revised October 2011 ISBN: 9781860164514 Price: $£ 8.00$ UK, $£ 10.00$ overseas (inc post and packing)
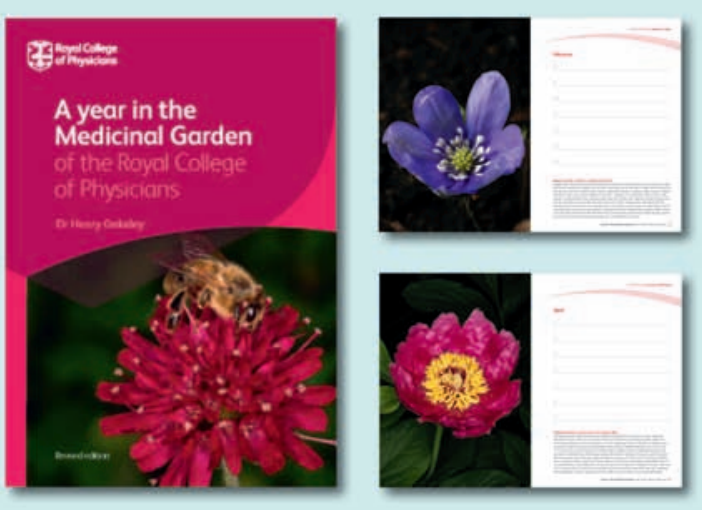